\title{
Effects of Low-temperature Tumbling on the Quality Characteristics of Restructured Chicken Breast Ham
}

\author{
Si-Young Kim ${ }^{1,2}$, Ji-Hun Choi ${ }^{2}$, Yun-Sang Choi ${ }^{3}$, Hack-Youn Kim ${ }^{4}$, Kwang-II Ahn², Hyun-Wook Kim², \\ Tae-Hyun $\mathrm{Kim}^{2}$, Dong-Heon Song ${ }^{2}$, and Cheon-Jei Kim \\ ${ }^{1}$ Dongwon F\&B, Seongnam 462-120, Korea \\ ${ }^{2}$ Department of Food Science and Biotechnology of Animal Resources, Konkuk University, Seoul 143-701, Korea \\ ${ }^{3}$ Food and Biological Resources Examination Division, Korean Intellectual Property Office, Daejeon 302-701, Korea \\ ${ }^{4}$ Department of Animal Resources Science, Kongju National University, Yesan 340-702, Korea
}

\begin{abstract}
The aim of this study was to evaluate the effects of tumbling condition (time and temperature) on the quality characteristics of restructured chicken breast ham. Tumbling conditions were 10,30 , and $60 \mathrm{~min}$ at 3 or $-3^{\circ} \mathrm{C}$, respectively. After tumbling, quality characteristic regarding the treatments processed by each condition were measured. There were no significant differences in $\mathrm{pH}$ levels among tumbling time or temperature. Treatments involving $60 \mathrm{~min}$ of tumbling had significantly higher water holding capacity (WHC) than that tumbled for $10 \mathrm{~min}$, but WHC was not affected by the tumbling temperature. The tumbling condition at $-3^{\circ} \mathrm{C}$ for 60 min demonstrated the most effective cooking yields for restructured chicken breast ham. Myofibrillar protein solubility of treatments tumbled for $60 \mathrm{~min}$ had the highest value of all, regardless of tumbling temperature. The hardness of treatments tumbled at $-3^{\circ} \mathrm{C}$ were lower than those at $3^{\circ} \mathrm{C}$; however, the springiness of treatments tumbled for $60 \mathrm{~min}$ were significantly higher than those regarding the treatments tumbled for 10 and $30 \mathrm{~min}$. Therefore, tumbling technology for $30 \mathrm{~min}$ or more at $-3^{\circ} \mathrm{C}$ can produce restructured chicken breast ham of excellent quality.
\end{abstract}

Key words: tumbling, restructured ham, chicken breast, quality characteristic

\section{Introduction}

Restructured meat products are made from minced and/ or chopped muscles which are used to produce products with a consistent appearance and texture. There are various methods used to improve the quality of restructured meat products (Choi et al., 2008). Several methods, including use of superior raw material, improvement of processing conditions, and addition of additives, are used to improve the quality of restructured meat products. In part of these, the use of salt and phosphate enhances cohesiveness and cook yield in restructured meat products (Farouk et al., 2000; Raharjo et al., 1995). Schmidt and Trout (1982) reported that restructured meat products using salt and phosphate are related to the thermal binding of myofibrillar protein that is extracted from meat. Also, the curing process is used to improve the flavor and

\footnotetext{
*Corresponding author: Cheon Jei Kim, Department of Food Science and Biotechnology of Animal Resources, Konkuk University, Seoul 143-701, Korea. Tel: 82-2-450-3684, Fax: 82-2-444-6695, E-mail address: kimcj@konkuk.ac.kr
}

increase juiciness, and it contributes to improving tenderness and increasing the water holding capacity of meat products. This latter property is related to several aspects of the meat before and after cooking, besides directly influencing the yield of the process and the palatability of the product (Garcia et al., 2002). Marination is a popular technique used to tenderize and improve the flavor and succulence of meat (Lemos et al., 1999). Marination of broiler breast meat has become an integral part of the poultry industry due to the increase in consumer and restaurant demand for further-processed, ready-to-eat, convenience foods. Marination has also been used as a method of tenderization (Young et al., 1991; Young and Lyon, 1997a). Marination mixtures can be applied to the meat through soaking, injection, or vacuum tumbling, depending on type of meat product (Smith and Young, 2007).

Tumbling is the most severe kind of physical treatment involved in the processing of cured meats, serving to break down the structure of the muscle through the application of mechanical energy (Pietrasik and Shand, 2003). Additional tumbling can have an important role in obtaining good distribution of brine, enhancing brine absorp- 
tion, and facilitating protein extraction (Barbut, 2001). Boneless skinless breast fillets are usually tumble marinated under vacuum pressure. The vacuum tumbling process has been shown to increase marinade uptake in the meat (Young and Lyon, 1997a; Young and Smith, 2004) and improve cook yields (Young and Lyon, 1997b). Generally, marination of poultry meat increase tenderness as measured by objective shear or texture panels (Goodwin and Maness, 1984; Landes, 1972; Maki and Froning, 1987; Smith et al., 1991) and tumbling process are carried out in refrigerated states below $4^{\circ} \mathrm{C}$. However, very few studies have been reported the study on the quality changes of restructured chicken breast ham when tumbling at super-cooling temperature (less $0^{\circ} \mathrm{C}$ ). As an important factors, tumbling conditions such as time and temperature influence characteristics of final product.

Therefore, the objective of this study was to evaluate the effects of tumbling time $(10,30$, and $60 \mathrm{~min})$ and temperature $\left(3\right.$ and $\left.-3^{\circ} \mathrm{C}\right)$ on the quality characteristics of restructured chicken breast ham.

\section{Materials and Methods}

\section{Sample collection and process of restructured chicken breast ham}

Boneless, skinless chicken (Pectoralis major) fillets were obtained from commercial processing plants. Chicken breasts were initially ground through $\varnothing-13 \mathrm{~mm}$ plate. After ground meat, $2 \%$ salt and $0.3 \%$ phosphate based on total meat weight were added, and tumbling process using the tumbler (MKR-150C, Rühle GmbH., Germany) was carried out. Tumbling conditions were at 3 or $-3^{\circ} \mathrm{C}$ for 10,30 , and $60 \mathrm{~min}$, respectively. Also, all treatments were vacuum tumbled $(610 \mathrm{mmHg}, 8 \mathrm{rpm})$. The tumbled samples were stuffed into fibrous casing with $\varnothing-50 \mathrm{~mm}$ and heated in a water bath at $75^{\circ} \mathrm{C}$ for 60 min. And cooked samples were cooled at room temperature for 30 min (Fig. 1).

\section{pH measurements}

The $\mathrm{pH}$ values of uncooked and cooked sample were determined with a pH meter (Model 340, Mettler-Toledo $\mathrm{GmbH}$, Switzerland). The $\mathrm{pH}$ values of samples were measured by blending a $5 \mathrm{~g}$ sample with $20 \mathrm{~mL}$ distilled water for $60 \mathrm{~s}$ in a homogenizer at 8,000 rpm (Ultra-Turrax SK15, Janke \& Kunkel, Germany).

\section{Water Holding Capacity (WHC)}

The water holding capacity was measured by a modifi-

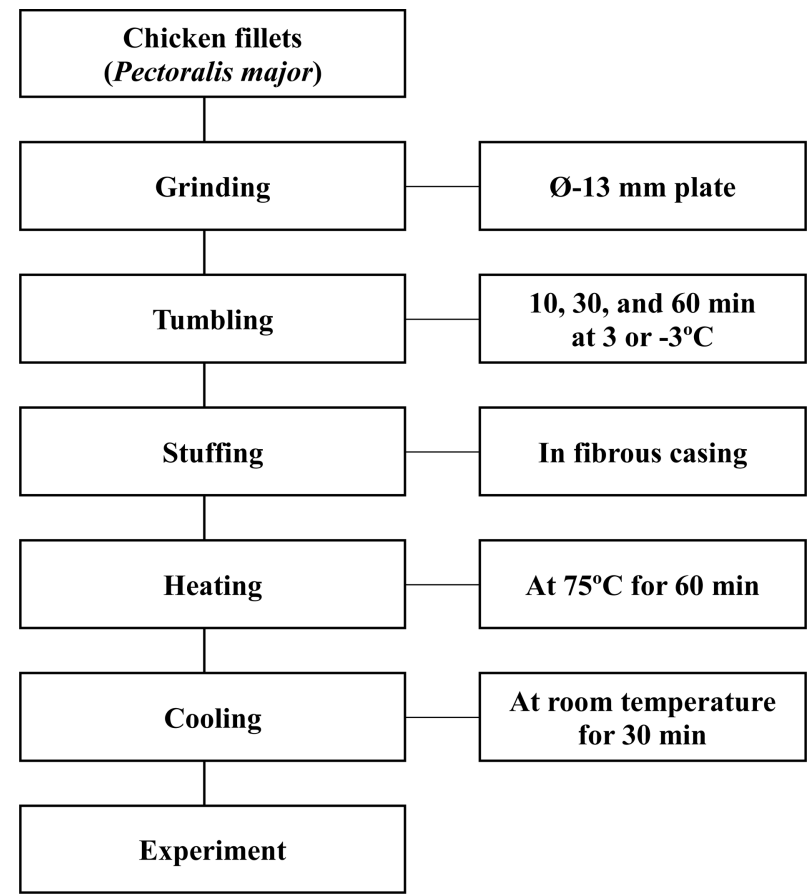

Fig. 1. The diagram of restructured chicken breast ham prepared with different tumbling time and temperature.

cation of the procedure of Grau and Hamm (1953). Briefly, a $300 \mathrm{mg}$ sample of muscle was placed in a filter press device (two plexiglass plate) and compressed for 3 min. WHC was calculated from duplicate samples as a ratio of the meat film area to the total area.

\section{Cooking yields}

Cooking yields (\%) were determined by calculating the weight differences of restructured chicken breast ham before and after cooking as follow:

Cooking yields $(\%)=($ restructured chicken breast ham weight after cooking $(\mathrm{g}) /$ restructured chicken breast ham weight before cooking $(\mathrm{g})) \times 100$

\section{Instrumental color evaluation}

Instrumental color of cooked samples was determined using a colorimeter (Minolta Chroma meter CR-210, Japan; illuminate $\mathrm{C}$, calibrated with a white plate, CIE L ${ }^{*}$ $=+97.83, \mathrm{CIE} \mathrm{a}^{*}=-0.43, \mathrm{CIE} \mathrm{b}^{*}=+1.98$ ). Twelve measurements for each of three locations on surface of cooked restructured chicken breast ham were taken. CIE L ${ }^{*}$ (lightness), CIE $\mathrm{a}^{*}$ (redness), and CIE $\mathrm{b}^{*}$ (yellowness) values were recorded.

\section{Proteins extraction and solubility determination}

The protein solubility of myofibrillar proteins was mea- 
sured. Tumbled sample (100 g) was weighed into a beaker and then $900 \mathrm{~mL}$ of $2 \% \mathrm{NaCl}$ solution was added. To measure the concentration of myofibrillar protein flowed out from inside of meat to surface, the sample and solution were washed using a stirrer for $10 \mathrm{~min}$. After straining; through a sieve with $1 \times 1 \mathrm{~mm}$ mesh, the protein solubility of the filtrate was determined by the Biuret method (Gornall et al., 1949). And then filtrates were centrifuged $(10,000 \mathrm{rpm}, 30 \mathrm{~min})$ to determine the solubility within meat, and the supernatant was clarified by a filtration through Whatman No. 1 filter paper. The protein solubility of the filtrate was also measured by the Biuret method.

\section{Texture profile analysis (TPA)}

Texture profile analysis was performed to comparison of textural properties due to tumbling conditions, and was measured using a texture analyzer (TA-XT2i, Stable Micro Systems Ltd., England) at room temperature. Prior to analysis, samples were allowed to equilibrate to room temperature $\left(20^{\circ} \mathrm{C}, 3 \mathrm{~h}\right)$. Cooked samples were cut to 20 $\mathrm{mm}$ height. The conditions of texture analysis were as follows: pre-test speed $2.0 \mathrm{~mm} / \mathrm{s}$, post-test speed $5.0 \mathrm{~mm} /$ $\mathrm{s}$, maximum load $2 \mathrm{~kg}$, head speed $2.0 \mathrm{~mm} / \mathrm{s}$, distance 8.0 $\mathrm{mm}$, force $5 \mathrm{~g}$. The calculation of TPA values was obtained by graphing a curve using force and time plots.

\section{Statistical analysis}

An analysis of variance were performed on all the variables measured using the General Linear Model (GLM) procedure of the SAS statistical package (SAS, 2008). The Duncan's multiple range test $(p<0.05)$ was used to determine difference between treatment means.

\section{Results and Discussion}

\section{pH value, water holding capacity (WHC), and color}

The $\mathrm{pH}$ value, water holding capacity, and color of restructured chicken breast ham with different tumbling time and temperature were shown in Table 1 . The $\mathrm{pH}$ values of raw restructured chicken breast ham ranged from 5.99 to 6.04. After cooking, the $\mathrm{pH}$ value slightly increased, however, there were no significant differences in $\mathrm{pH}$ value among the all treatments $(p>0.05)$.

Regardless of the temperature, longer tumbling times resulted in an increase in the WHC of raw restructured chicken breast hams. Treatment tumbled at $-3^{\circ} \mathrm{C}$ for 60 min had significantly higher WHC than that tumbled at $-3^{\circ} \mathrm{C}$ for $10 \mathrm{~min}(p<0.05)$. However, WHC was not affected by the tumbling temperature $(p>0.05)$. There are some reports indicating that longer tumbling time (to $16 \mathrm{~h}$ ) greatly influenced the hydration properties associated with WHC in injected roast beef (Pietrasik and Shand, 2004). The effect of massaging time on bind and yield of sectioned and formed hams showed that although the largest increase in cooking loss was viewed at $1 \mathrm{~h}$ of massaging, longer massaging had no changes in cooking loss under containing $2 \% \mathrm{NaCl}$ and $0.5 \%$ phosphate. And this result was affected by the presence of phosphate resulted in the increase in WHC (Siegel et al., 1978b).

Table 1. Effects of tumbling time and temperature on the pH value, water holding capacity (WHC), and cooked color of restructured chicken breast ham

\begin{tabular}{|c|c|c|c|c|c|}
\hline \multirow{2}{*}{\multicolumn{2}{|c|}{ Traits }} & \multirow{2}{*}{$\begin{array}{c}\text { Tumbling } \\
\text { temperature }\left({ }^{\circ} \mathrm{C}\right)\end{array}$} & \multicolumn{3}{|c|}{ Tumbling time (min) } \\
\hline & & & 10 & 30 & 60 \\
\hline \multirow{4}{*}{$\mathrm{pH}$} & \multirow{2}{*}{ Before cooking } & 3 & $6.04 \pm 0.04$ & $6.03 \pm 0.03$ & $6.02 \pm 0.02$ \\
\hline & & -3 & $6.00 \pm 0.05$ & $5.99 \pm 0.04$ & $6.01 \pm 0.03$ \\
\hline & \multirow{2}{*}{ After cooking } & 3 & $6.25 \pm 0.03$ & $6.25 \pm 0.04$ & $6.26 \pm 0.03$ \\
\hline & & -3 & $6.23 \pm 0.03$ & $6.23 \pm 0.03$ & $6.25 \pm 0.04$ \\
\hline \multirow{2}{*}{\multicolumn{2}{|c|}{ Water holding capacity (\%) }} & 3 & $79.64 \pm 1.71$ & $80.33 \pm 0.74$ & $81.95 \pm 1.78$ \\
\hline & & -3 & $80.33 \pm 0.74^{\mathrm{B}}$ & $81.30 \pm 1.39^{\mathrm{AB}}$ & $82.20 \pm 2.59^{\mathrm{A}}$ \\
\hline \multirow{2}{*}{\multicolumn{2}{|c|}{ CIE L* value (lightness) }} & 3 & $81.74 \pm 1.95$ & $82.22 \pm 1.18^{\mathrm{a}}$ & $81.01 \pm 1.07$ \\
\hline & & -3 & $81.83 \pm 0.89^{\mathrm{A}}$ & $79.78 \pm 2.00^{\mathrm{Bb}}$ & $80.04 \pm 0.76^{\mathrm{B}}$ \\
\hline \multirow{2}{*}{\multicolumn{2}{|c|}{ CIE a* value (redness) }} & 3 & $2.10 \pm 0.37^{\mathrm{Aa}}$ & $1.56 \pm 0.86^{\mathrm{AB}}$ & $1.11 \pm 0.56^{\mathrm{B}}$ \\
\hline & & -3 & $2.03 \pm 0.29^{\mathrm{Ab}}$ & $1.50 \pm 0.35^{\mathrm{B}}$ & $1.13 \pm 0.75^{\mathrm{B}}$ \\
\hline \multirow{2}{*}{\multicolumn{2}{|c|}{ CIE b* value (yellowness) }} & 3 & $12.67 \pm 0.75^{\mathrm{A}}$ & $11.52 \pm 1.29^{\mathrm{B}}$ & $11.14 \pm 1.25^{\mathrm{B}}$ \\
\hline & & -3 & $12.61 \pm 0.92^{\mathrm{A}}$ & $12.24 \pm 1.15^{\mathrm{AB}}$ & $11.73 \pm 0.45^{\mathrm{B}}$ \\
\hline
\end{tabular}

All values are means \pm SD.

${ }^{\mathrm{A}, \mathrm{B}}$ Means values with different superscript within same row are significantly different $(p<0.05)$.

${ }^{\mathrm{a}, \mathrm{b}}$ Means values with different superscript within same column are significantly different $(p<0.05)$. 
For color of cooked restructured ham, in the case of tumbling time, lightness of the treatment tumbled for 30 and $60 \mathrm{~min}$ at $-3^{\circ} \mathrm{C}$ had a significantly lower in those tumbled for $10 \mathrm{~min}(p<0.05)$. The redness and yellowness were significantly higher in the treatment tumbled $10 \mathrm{~min}$ than in those tumbled for $60 \mathrm{~min}(p<0.05)$. For tumbling temperature, lightness are significantly higher in the treatment tumbled at $3^{\circ} \mathrm{C}$ for $30 \mathrm{~min}$ than in that tumbled at $3^{\circ} \mathrm{C}$ for $30 \mathrm{~min}(p<0.05)$. Also, the redness are significantly higher in the treatment tumbled at $3^{\circ} \mathrm{C} 10$ min than in these tumbled at $-3^{\circ} \mathrm{C} 10 \mathrm{~min}(p<0.05)$. The yellowness values of restructured hams decreased with increasing tumbling time. The redness values in restructured chicken breast hams significantly differed at tumbling time for 10 $\min$.

\section{Cooking yields and myofibrillar protein solubility}

The effects of tumbling time and temperature on the cooking yields of restructured chicken breast ham were shown in Fig. 2. The cooking yields of restructured chicken breast ham increased with increasing tumbling time, regardless of tumbling temperature. As a similar result, the cooking yield of chicken tikka increased with increasing vacuum tumbling time from $65.72 \%$ (no tumbling) to $80.75 \%$ (45 min) (Bharti et al., 2011). Also, according to the tumbling temperature, the cooking yields tumbled at $-3^{\circ} \mathrm{C}$ treatments were significantly higher than those tumbled at $3^{\circ} \mathrm{C}$ treatments $(p<0.05)$. Therefore, products yields

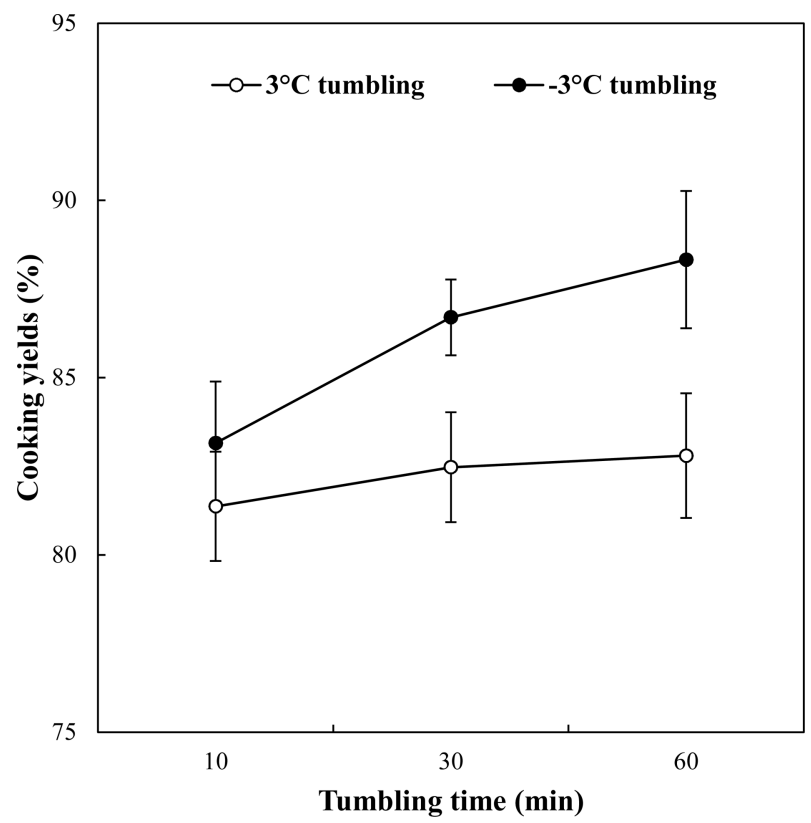

Fig. 2. The comparison on cooking yields of restructured chicken breast ham prepared with different tumbling time and temperature. of restructured chicken breast ham were the most effective tumbling condition at $-3^{\circ} \mathrm{C}$ for $60 \mathrm{~min}$.

Myofibrillar protein solubility of cured ground chicken breasts with different tumbling time and temperature before and after centrifuged was shown in Fig. 3. Myofibrillar protein solubility of treatment tumbled for $60 \mathrm{~min}$ had the highest value of all, regardless of tumbling temperature $(p<0.05)$. Treatment tumbled at $-3^{\circ} \mathrm{C}$ had higher myofibrillar protein solubility than that tumbled at $3^{\circ} \mathrm{C}$ in treatments tumbled for each time $(p<0.05)$. Generally, increased tumbling time improves the protein solubility of myofibrillar proteins. This result agreed with those of Solomon and Schmidt (1980), who reported that significantly greater crude myosin of beef was obtained with increased mixing time under vacuum condition. Mechanical mixing results in cell destruction and has been observed to promote surface exudation of soluble proteins which function as excellent binders (Wang and Chen, 1991). Offer and Trinick (1983) reported that the increased ionic strength would result in more solubilization of muscle proteins and thus an increase in the cooking yield of the product.

\section{Texture profile analysis}

The texture profile analysis (TPA) of cooked restructured chicken breast hams were shown in Table 2. For the treatments tumbled at $3^{\circ} \mathrm{C}$, hardness of treatment tumbled for $60 \mathrm{~min}$ was significantly lower than that of treatment

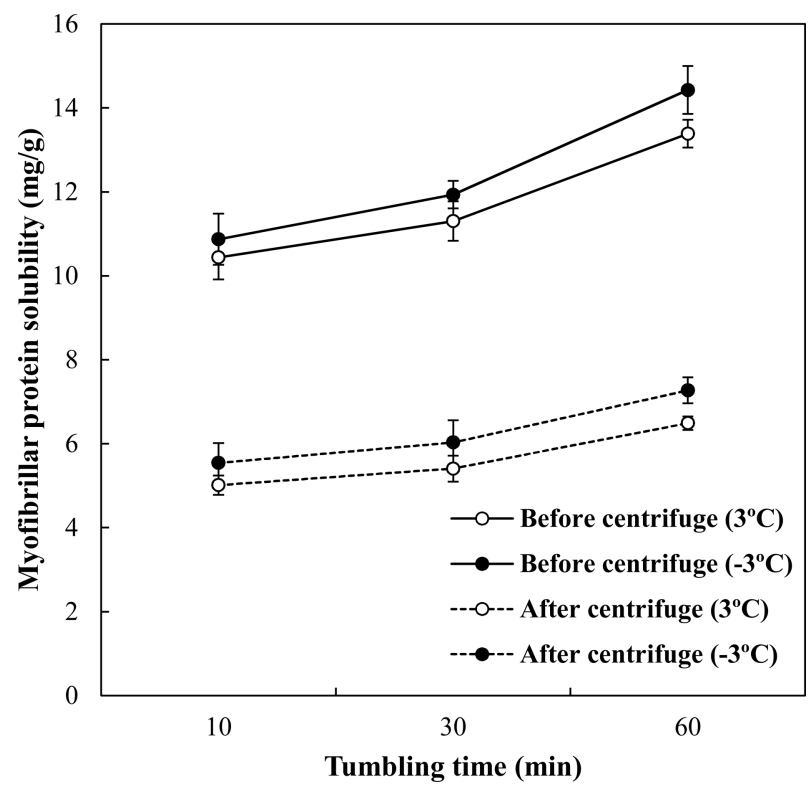

Fig. 3. The comparison on myofibrillar protein solubility of restructured chicken breast ham prepared with different tumbling time and temperature. The centrifuge was conducted at $10,000 \mathrm{rpm}$ for $30 \mathrm{~min}$. 
Table 2. Effects of tumbling time and temperature on textural properties of restructured chicken breast ham

\begin{tabular}{ccccc}
\hline \hline \multirow{2}{*}{ Traits } & Tumbling & \multicolumn{3}{c}{ Tumbling time (min) } \\
\cline { 3 - 5 } & temperature $\left({ }^{\circ} \mathrm{C}\right)$ & 10 & 30 & 60 \\
\hline \multirow{2}{*}{ Hardness $(\mathrm{kg})$} & 3 & $0.62 \pm 0.05^{\mathrm{A}}$ & $0.61 \pm 0.05^{\mathrm{AB}}$ & $0.58 \pm 0.06^{\mathrm{B}}$ \\
& -3 & $0.60 \pm 0.04^{\mathrm{A}}$ & $0.60 \pm 0.05^{\mathrm{A}}$ & $0.57 \pm 0.04^{\mathrm{B}}$ \\
\hline \multirow{2}{*}{ Springiness } & 3 & $0.83 \pm 0.07$ & $0.83 \pm 0.06$ & $0.83 \pm 0.07^{\mathrm{b}}$ \\
& -3 & $0.84 \pm 0.05^{\mathrm{B}}$ & $0.86 \pm 0.06^{\mathrm{AB}}$ & $0.89 \pm 0.08^{\mathrm{Aa}}$ \\
\hline \multirow{2}{*}{ Cohesiveness } & 3 & $0.56 \pm 0.04$ & $0.58 \pm 0.03$ & $0.56 \pm 0.04$ \\
\hline \multirow{2}{*}{ Gumminess $(\mathrm{kg})$} & -3 & $0.58 \pm 0.04$ & $0.59 \pm 0.04$ & $0.57 \pm 0.04$ \\
\hline \multirow{2}{*}{ Chewiness $(\mathrm{kg})$} & -3 & $0.35 \pm 0.04$ & $0.35 \pm 0.04$ & $0.33 \pm 0.04$ \\
& 3 & $0.35 \pm 0.03^{\mathrm{A}}$ & $0.35 \pm 0.04^{\mathrm{A}}$ & $0.32 \pm 0.04^{\mathrm{B}}$ \\
\hline
\end{tabular}

All values are means \pm SD.

${ }_{\mathrm{A}, \mathrm{B}}$ Means values with different superscript within same row are significantly different $(p<0.05)$.

${ }^{\mathrm{a}, \mathrm{b}}$ Means values with different superscript within same column are significantly different $(p<0.05)$.

tumbled for $10 \min (p<0.05)$. For the treatment tumbled at $-3^{\circ} \mathrm{C}$, hardness was a similar tendency compared to treatments tumbled at $3^{\circ} \mathrm{C}$. However, there were no significant difference in hardness between $3^{\circ} \mathrm{C}$ and $-3^{\circ} \mathrm{C}$ in identical tumbling time $(p>0.05)$. The increase in tumbling time led to improve the springiness regardless tumbling temperature, moreover, the treatment tumbled at $-3^{\circ} \mathrm{C}$ for $60 \mathrm{~min}$ had significantly a higher springiness than the treatment tumbled at $3^{\circ} \mathrm{C}(p<0.05)$. The cohesiveness, gumminess, and chewiness of restructured chicken breast ham did not affected by tumbling time and temperature. It has been reported that the increased time of physical manipulation significantly increased the amount of extracted crude myosin in a ground beef system (Solomon and Schmidt, 1980). Shackelford et al. (1989) reported that increased massaging time from 2 to $3 \mathrm{~h}$ caused improvement of tenderness of pre-cooked beef roast. The extracted proteins improve the binding strength, in which time is required either to allow them to react with the salt and/or phosphate, or to allow their orientation to maximize their contribution to binding (Siegel et al., 1978a). In our results, we found that the restructured ham prepared with chicken breast tumbled at $-3^{\circ} \mathrm{C}$ for $60 \mathrm{~min}$ provides tender and flexible textural properties compared to the other tumbling condition. The improvement of textural properties due to tumbling condition is greatly associated with the degree of myofibrillar protein solubility.

The results of this study show that tumbling time affected the quality characteristics of restructured chicken breast ham such as cooking yields, WHC, a part of texture properties, and myofibrillar protein solubility. Especially if tumbled $30 \mathrm{~min}$ or more, it could be obtained the high quality restructured chicken ham. Also, tumbling technology at $-3^{\circ} \mathrm{C}$ might be an effective method to produce the restructured chicken breast ham improved cooking yield and textural properties.

\section{Acknowledgements}

This study was supported by Technology Development Program (608001-05-1-SB410) for Agriculture and Forestry, Ministry for Agriculture, Forestry and Fisheries, Republic of Korea. This article was partially supported by the Brain Korea 21 (BK 21) Project from Ministry of Education and Human Resources Development, Republic of Korea.

\section{References}

1. Barbut, S. (2001) Meat processing-Equipment. In: Poultry products processing. CRC Press. NY.

2. Bharti, S. K., Anita, B., Das, S. K., and Bisawas, S. (2011) Effect of vacuum tumbling time on physico-chemical, microbiological and sensory properties of chicken tikka. J. Stored Prod. Postharvest Res. 2, 139-147.

3. Choi, J. H., Jeong, J. Y., Han, D. J., Choi, Y. S., Kim, H. Y., Lee, M. A., Lee, E. S., Paik, H. D., and Kim, C. J. (2008) Effects of pork/beef levels and various casings on quality properties of semi-dried jerky. Meat Sci. 80, 278-286.

4. Farouk, M. M., Hall, W. K., and Swan, J. E. (2000) Attributes of beef sausage batters, patties and restructured roasts from two boning systems. J. Muscle Foods 11, 197-212.

5. Garcia, R. G., Mendes, A. A., Garcia, E. A., Nääs, I. A., Moreira, J., Almeida, I. C. L., and Takita, T. S. (2002) Effect of stocking density and sex on feathering, body injury and breast meat quality of broiler chickens. Braz. J. Poultry Sci. 
4, 1-9.

6. Goodwin, T. L. and Maness, J. B. (1984) The influence of marination, weight, and cooking technique on tenderness of broilers. Poultry Sci. 63, 1925-1929.

7. Gornal, A. G., Bardawill, C. J., and David, M. M. (1949) Determination of serum proteins by means of the Biuret reaction. J. Biol. Chem. 177, 751-766.

8. Grau, R. and Hamm, R. (1953) Eine einfache methode zur bestimmung der wasserbindung in muskel. Naturwissenschaften 40, 29-31.

9. Landes, D. R. (1972) The effects of polyphosphates on several organoleptic, physical, and chemical properties of stored pre-cooked frozen chickens. Poultry Sci. 51, 641-646.

10. Lemos, A. L. S. C., Nunes, D. R. M., and Viana, A. G. (1999) Optimization of the still-marinating process of chicken parts. Meat Sci. 52, 227-234.

11. Maki, A. A. and Froning, G. W. (1987) Effect on the quality characteristics of turkey breast muscle of tumbling whole carcasses in the presence of salt and phosphate. Poultry Sci. 66, 1180-1183.

12. Offer, G. and Trinick, J. (1983) On the mechanism of waterholding in meat: The swelling and shrinking of myofibrils. Meat Sci. 8, 245-281.

13. Pietrasik, Z. and Shand, P. J. (2003) The effect of quantity and timing of brine addition on water binding and textural characteristics of cooked beef rolls. Meat Sci. 65, 771-778.

14. Pietrasik, Z. and Shand, P. J. (2004) Effect of blade tenderization and tumbling time on the processing characteristics and tenderness of injected cooked roast beef. Meat Sci. 66, 871-879.

15. Raharjo, S., Dexter, D. R., Worfel, R. C., Sofos, J. N., Solomon, M. B., Shults, G. W., and Schmidt, G. R. (1995) Quality characteristics of restructured beef steaks manufactured by various techniques. J. Food Sci. 60, 68-71.

16. SAS (2008) SAS/STAT Software for PC. Release 9.2, SAS Institute Inc., Cary, NC, USA.

17. Schmidt, G. R. and Trout, G. R. (1982) Chemistry of binding. In: Meat Sci. Tech. Int. Symp. Proc., Lincoln, NE, pp. 265278.

18. Shackelford, S. D., Reagan, J. O., Mann, T. F., Lyon, C. E., and Miller, M. F. (1989) Effects of blade tenderization, vacuum massage time and salt level on chemical, textural and sensory characteristics of precooked chuck roasts. J. Food Sci. 54, 843-845, 905.

19. Siegel, D. G., Theno, D. M., and Schmidt, G. R. (1978a) Meat massaging: the effects of salt, phosphate and massaging on the presence of specific skeletal muscle proteins in the exudates of a sectioned and formed ham. J. Food Sci. 43, 327330.

20. Siegel, D. G., Theno, D. M., Schmidt, G. R., and Norton, H. W. (1978b) Meat massaging: the effects of salt, phosphate and massaging on cooking loss, binding strength and exudates composition in sectioned and formed ham. J. Food Sci. 43, 331-333.

21. Smith, D. P. and Young, L. L. (2007) Marination pressure and phosphate effects on broiler breast fillet yield, tenderness, and color. Poultry Sci. 86, 2666-2670.

22. Smith, D. P., Fletcher, D. L., and Papa, C. M. (1991) Evaluation of duckling breast meat subjected to different methods of further processing and cooking. J. Muscle Foods 2, 305310 .

23. Solomon, L. W. and Schmidt, G. R. (1980) Effect of vacuum and mixing time on the extractability and functionality of pre- and postrigor beef. J. Food Sci. 45, 283-287.

24. Wang, S. W. and Chen, T. C. (1991) Surface protein of broiler meat chunks as obtained by washing. J. Muscle Foods 2, 253-262.

25. Young, L. L. and Lyon, C. E. (1997a) Effect of calcium marination on biochemical and textural properties of pre-rigor chicken breast meat. Poultry Sci. 76, 197-201.

26. Young, L. L. and Lyon, C. E. (1997b) Effect of postchill aging and sodium tripolyphosphate on moisture binding properties, color, and Warner-Bratzler shear values of chicken breast meat. Poultry Sci. 76, 1587-1590.

27. Young, L. L. and Smith, D. P. (2004) Effect of vacuum on moisture absorption and retention by marinated broiler fillets. Poultry Sci. 83, 129-131.

28. Young, L. L., Garcia, J. M., and Papa, C. M. (1991) Effect of divalent cations on biochemical and functional parameters of pre- and postrigor chicken breast fillets. Poultry Sci. 70, 2354-2358.

(Received 2012.2.21/Revised 2012.4.9/Accepted 2012.4.17) 